children too much to rob them of any of their joys. But the truth, if properly told, is more fascinating than fiction and will do infinitely more good.

In the intermediate grades school gardens, home experiments, and school projects may be utilized. In the Grammar Grades laboratory and field work may be ably done and insect collections made. That this motivates the work in the whole school is subscribed to by many schools in the United States where this is in part carried out.

I shall not present here my outline of the course for the various grades, as it is not my intention to thrust upon others my ideas as to content but rather to present an argument for the course which should be standardized by the blending of ideas of a large number of capable teachers and students. There will be a tendency, no doubt, as was the case in General Science, to emphasize the divisions of Seience in which the writer of text books is especially versed or interested. But no course of study has ever stood the test of time but has been subjected to the tests of usefulness and efficiency. So, too, the work in Nature study will be tested and varied until its plane of greatest good has been determined. It will be the object of criticism and ridicule, but like the others it will soon, perhaps sooner than we think, find its channel and when this has been accomplished; when it begins to function properly, this old world of ours will be a better place in which to live.

\title{
THE OUTLINE OF A COURSE IN PRACTICAL CHEMISTRY FOR GIRLS.
}

By Charles E. Dull,

South Side High School, Newark, N. J.

Feeling that the college preparatory course in chemistry does not meet the needs of students who enter business directly from high school and that it is not well suited to girls who enter normal school, we are giving courses in chemistry which we believe such students will find of more value to them than the regular preparatory work.

In the chemistry for girls, the nature of chemical action, how chemical changes are brought about, and the demonstration of the various classes of chemical change are taught in practically the same manner as in the regular preparatory chemistry.

In the study of oxygen and hydrogen, their preparation is left entirely to the laboratory. In discussing their properties, 
emphasis is placed upon the special properties which make them fitted for certain uses.

After the general properties of an acid have been discussed and demonstrated, several samples are shown, including not only the strong mineral acids, but such acids as boric, acetic, citric, tartaric, tannic and oxalic. Since practically all of these are found in every household, their occurrence and uses are studied briefly at this time.

In a similar manner the general characteristics of bases are taken up. The vigorous action of soluble bases on fats and oils is briefly considered. With these bases aqua ammonia as a weaker base is contrasted. Demonstrations are used to show that washing soda, borax and soap have an alkaline reaction in solution, thus explaining their action as solvents of grease.

Eight or ten salts are used to show the variation in color, solubility, crystalline structure and chemical behavior which leads to so many different uses.

The question of theory is rather a difficult one in such a course. It seems to me that each pupil should have a clear conception of atomic weight, the atomic theory and the law of definite proportions. Each one should know the significance of symbols, and formulas, and be able to interpret equations. I expect the pupils to know how to find the molecular weight of a compound from the tables of atomic weights, to figure its percentage composition and to solve simple problems involving chemical equations.

I treat nomenclature quite as fully as in the regular course and valence a little more briefly. The treatment of solutions does not vary from that of the regular course.

The subject of fuels and illuminants is considered with combustion and oxidation. Wood, the various kinds of coal, oil and gas are compared with respect to cost; fuel value and waste products. If the class has not studied physics, we include diagrams showing the proper regulation of drafts, check-drafts and dampers. Diagrams of smoke consumers are used to show the effect of more efficient oxidation. These topies include the principles of extinguishing fire; applications of the three methods; and references to fireproof materials and the fire-proofing of cloth.

The operation of the bunsen burner is compared with the ordinary gas burner to show how to secure the highest efficiency. Coal-gas, water-gas and acetylene are studied as fuels and il- 
luminants. Comparison is made between the fish-tail burner and the gas mantle as to efficiency.

In the lesson on the composition of the air, no difference is made except the greater emphasis upon methods of ventilation, the use of ozonized air and the effect of relative humidity.

In the chapter on water, the color, odor, and turbidity are first studied. The distinction between pure and wholesome water is emphasized as well as the effect of organic matter in drinking water. Natural soil filtration, mechanical filtration, boiling, aeration, coagulum precipitation and distillation are studied in their relation to water purification. The use of ozone, chlorine, and copper sulphate as methods of ehemical purification are discussed. This chapter also includes such topics as the value of hard water for drinking purposes, its disadvantages for use in laundries, dye-works, paper-mills and steam boilers, and the methods used for softening hard waters.

Considerable attention is given to the study of foods, including the following topics: Starch, its oceurrence and conversion into glucose and dextrine; the occurrence of several sugars and their importance as food; proteins as found in meat, eggs, flour, milk and legumes; the occurrence and extraction of fats and oils; and emulsions and saponification.

Following a comparison of the values of the various methods of cooking, the need for preserving foods that are not to be used for immediate consumption is shown by a brief discussion of molds, yeasts and bacteria. Especial emphasis is placed on the study of conditions favorable to their growth; this is followed by a discussion of the various methods of preservation: Canning, the use of sugar, pickling, smoking, drying, refrigeration, sterilization and pasteurization of milk, and the use of chemicals.

Some of the important foods are studied in greater detail. In bread-making the study of the action of yeast is followed by a discussion of the action of such leavening agents as baking powder, soda and sour milk, molasses, or simple aeration. The use of shortening is briefly discussed.

The value of milk as a food includes a study of its source, how easily it may be contaminated, souring due to lactic acid bacteria, and certified and condensed milk. Such foods as cream, icecream, butter and oleomargarine are studied in class. A brief study of such beverages as tea, coffee, and cocoa is included at this time. In the study of foods the most common adulterants are discussed, the nature of adulterants, and the objections to their use; whether injurious or a cheaper substitute. 
Since several organic substances find extensive use in the home or the arts, the properties and use of the following are taken up: Grain, wood and denatured alcohol, carbolic acid, glycerine, formaldehyde, chloroform, iodoform, carbon tetrachlorid, and a few esters and organic acids.

Under textiles we study the source of the various fibers and the action of chemicals on these fibers. This furnishes us a basis for the laboratory tests for these fibers and also makes the chemistry of bleaching and stain removal more intelligible.

In the study of laundering the methods of making soap are considered, the quality of soap, the action of free alkali, adulterants and fillers, the use of special soaps and cleansing agents and the need for the use of bluing, and the action of the various kinds.

The study of paints, oils and varnishes includes a comparison of zine and lead as paint bases, the action of linseed oil, the use of pigments, stains and driers, and a discussion of the various kinds of varnishes.

Comparatively little time is given to the study of the metals. The physical and chemical properties that make such metals as tin, lead, iron, zinc, silver and aluminum useful in the household are studied. Such topics as the action of alkalies on aluminum cooking utensils, the solvent action of some drinking waters on lead pipe, the tarnishing of silver in the presence of sulfids and the use of such action in making oxidized silver, the rusting of iron and the use of tin or zinc as a protective coating, the use of alloys and plated ware, and the methods of cleaning and polishing metals form the bulk of the work on metals.

The manufacture of the various kinds of glass and the discussion of the different kinds of pottery are topics which are given a very brief consideration.

The majority of the students find time to perform nearly all the experiments in the following list:

1. Preparation and properties of oxygen.

2. Preparation and properties of hydrogen.

3. Preparation and properties of hydrochloric acid (typical).

4. Preparation and properties of sodium and caleium hydroxides.

5. Preparation of salts. (Illustrating three methods.)

6. Presence of water in salts and its effects.

7. Quantitative determination of water in cryst, barium chloride.

8. Preparation of solutions; saturation; effect of temperature.

9. Destructive distillation of wood and coal. (Fuels and illuminants).

10. Properties of carbon; use as deodorizer and decolorizer.

11. Preparation and properties of carbon dioxid.

12. Distillation; coagulum purification of water.

13. Preparation and study of hard waters. Softening of hard waters. 
14. Tests for simple impurities in drinking water.

15. Test for stareh in several foods.

16. Test for glueose in several foods.

17. Test for proteins in several foods.

18. Test for fats and oils in several foods.

19. Milk; Babcock test; lactometer test; preparation of pasteurized milk; effeet of rennin (junket tablets).

20. Preparation of baking powder. Tests of commercial powders.

21. Tests for preservatives: (a) formaldehyde in milk; (b) boric acid in wafers, ice-cream cones and milk; (c) salicylic acid or benzoic acid in catsup, jams, ete.; (d) sulfites in sausage and hamburg steak; (e) saccharin in canned corn.

22. Tests for adulterants. Selections are made from the following:

(a) Starch and gelatine in ice-cream; (b) turmeric in mustard;

(c) coal-tar colors in candy, jellies or butter; (d) chicory or cereals in coffee; (e) cottonseed oil in olive oil; (f) oleomargarine or process butter for butter; $(\mathrm{g})$ copper salts in canned vegetables; (h) adulterants in vanilla or lemon extract; (i) adulterants in maple syrup; (j) glucose in candy; (k) manufactured vinegar for eider vinegar.

23. Test rancidity of butter or olive oil.

24. Test for alcohol in drugs; per cent of alcohol in drugs.

25. Tests for wood alcohol as a substitute for alcohol.

26. Extract eaffein from coffee; thein from tea; test "Kaffee Hag."

27. Test headache powders for acetanilid.

28. Determine acidity of vinegar.

29. Determine purity of baking soda and cream of tartar.

30. Determine amount of soluble matter in tea.

31. Determine the amount of water oysters lose by drainage.

32. Examination of fibers; action of chemicals on linen, wool, silk and cotton.

33. Analysis of mixed fabries.

34. Soap making. Free alkali in soap. Insoluble matter in soap.

35. Removal of stains: ink, grease, grass, coffee, tea, fruit, vaseline, mildew, iodin.

36. Preparation of aluminum hydroxid and its use with logwood and alizarin as a mordant.

37. Dyeing; direct dyes; basic dyes.

38. Study of solutions of resins in sodium hydroxid, linseed oil, alcohol and turpentine as varnishes.

39. Photography; blue prints.

40. Test paper, cloth, etc., for arsenic. (Gutzeit test.):

\section{COLLEGE ENTRANCE EXAMINATION BOARD QUESTIONS IN CHEMISTRY.}

By Henry Lester Gerry,

Worcester Academy, Worcester, Mass.

Recently the writer has taken occasion to examine rather carefully the questions in chemistry set by the College Entrance Examination Board during the past ten years. This was done with the view of determining, if possible, the portions of elementary chemistry which the examiners seem to have considered most important or, at least, have asked most frequently. Such an analysis as this has been does not lend itself easily to verbal description; nevertheless, it is the purpose of this paper to try to point out some of the conclusions that may be drawn 